\title{
Factors influencing age at diagnosis of primary ciliary dyskinesia in European children
}

\author{
C.E. Kuehni*, T. Frischer" ${ }^{\#}$ M-P.F. Strippoli*, E. Maurer*, A. Bush ${ }^{\top}$, K.G. Nielsen+, \\ A. Escribano ${ }^{\xi}$, J.S.A. Lucas ${ }^{f}$, P. Yiallouros**, H. Omran ${ }^{\# \#, ~ E . ~ E b e r ~}{ }^{*}$, \\ C. O'Callaghan ${ }^{++}$, D. Snijders ${ }^{\S \S}$ and A. Barbato ${ }^{\S \S}$ for the ERS Task Force on Primary \\ Ciliary Dyskinesia in Children ${ }^{f f}$
}

ABSTRACT: Primary ciliary dyskinesia (PCD) is a hereditary disorder of mucociliary clearance causing chronic upper and lower airways disease. We determined the number of patients with diagnosed PCD across Europe, described age at diagnosis and determined risk factors for late diagnosis.

Centres treating children with PCD in Europe answered questionnaires and provided anonymous patient lists.

In total, 223 centres from 26 countries reported 1,009 patients aged $<20$ yrs. Reported cases per million children (for 5-14 yr olds) were highest in Cyprus (111), Switzerland (47) and Denmark (46). Overall, $57 \%$ were males and $48 \%$ had situs inversus. Median age at diagnosis was $5.3 \mathrm{yrs}$, lower in children with situs inversus $(3.5$ versus $5.8 \mathrm{yrs} ; \mathbf{p}<0.001)$ and in children treated in large centres (4.1 versus $4.8 \mathrm{yrs} ; \mathrm{p}=\mathbf{0 . 0 0 2}$ ). Adjusted age at diagnosis was $5.0 \mathrm{yrs}$ in Western Europe, $4.8 \mathrm{yrs}$ in the British Isles, $5.5 \mathrm{yrs}$ in Northern Europe, $6.8 \mathrm{yrs}$ in Eastern Europe and $6.5 \mathrm{yrs}$ in Southern Europe $(p<0.001)$. This strongly correlated with general government expenditures on health $(p<0.001)$.

This European survey suggests that PCD in children is under-diagnosed and diagnosed late, particularly in countries with low health expenditures. Prospective studies should assess the impact this delay might have on patient prognosis and on health economic costs across Europe.

KEYWORDS: Bronchiectasis, ciliary motility disorders, diagnosis, epidemiology, Kartagener syndrome, primary ciliary dyskinesia

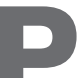

rimary ciliary dyskinesia (PCD) is a clinically and genetically heterogeneous group of hereditary disorders characterised by abnormal ciliary beat pattern, often with a low beat frequency and mostly, although not always, detectable ciliary ultra-structural abnormalities [1-7].

The main consequence is the impairment of mucociliary clearance from upper and lower airways leading to chronic airway infection and inflammation. The diagnosis should be suspected in children with chronic rhinitis and a chronic wet sounding cough, most frequently from birth.
Approximately $40-50 \%$ of affected children have situs inversus. The combination of situs inversus, bronchiectasis and sinusitis has been referred to as Kartagener syndrome. Other disease manifestations associated with PCD are caused by altered motility of cilia/flagellae of distinct cell types, including male infertility (sperm tail), hydrocephalus (ependymal cilia) and complex heart disease (nodal cilia) [8].

There are no representative international data on prevalence, age at diagnosis, burden of disease and prognosis in PCD patients. Available information comes from case series in single countries,
AFFILIATIONS

*Institute of Social and Preventive Medicine (ISPM), University of Berne, Berne, Switzerland.

\#Universitätsklinik für Kinder- und Jugendheilkunde, Vienna,

"Dept of Paediatrics and Adolescence Medicine, Medical University of Graz, Graz, Austria.

"Royal Brompton Hospital, London, 'Division of Infection, Inflammation and Immunity, University of Southampton School of Medicine, Southampton, ${ }^{++}$Division of Child Health, Dept of Infection, Immunity and Inflammation, University of Leicester, Leicester, UK. +Danish Paediatric Pulmonary Service, Rigshospitalet, Copenhagen, Denmark. §University Clinic Hospital, University of Valencia, Valencia, Spain

${ }^{* *}$ Cyprus International Institute for Environmental and Public Health, Cyprus University of Technology, Limassol, Cyprus. \#\#Klinik und Poliklinik für

Allgemeinpaediatrie, University Hospital, Münster, Germany.

${ }^{\S \S}$ Dept of Paediatrics, University of Padova. Padova, Italy.

${ }^{f f} \mathrm{~A}$ full list of the ERS Task Force members and their affiliations can be found in the Acknowledgements section.

CORRESPONDENCE

T. Frischer

Universitätsklinik für Kinder- und Jugendheilkunde, Währingergürtel 18-20, 1090 Vienna, Austria E-mail: thomas.frischer@ meduniwien.ac.at

Received: Jan 042010 Accepted after revision: May 222010 
the largest consisting of 55 and 78 patients from the UK and the USA, respectively [4, 9]. Reported prevalence shows large variations, with estimates between 1 in 2,200 and 1 in 40,000, using different approaches [10-13]. Although early diagnosis is thought to reduce long-term pulmonary morbidity and prevent unnecessary investigations and unhelpful treatments, there is evidence suggesting that diagnosis is often delayed, primarily due to lack of awareness and difficulties in establishing the diagnosis [9].

The European Respiratory Society (ERS) Task Force on PCD in children recently published a consensus statement, which highlighted the poor evidence base on epidemiology, diagnosis and treatment of PCD in children [14]. To collect baseline data on the situation in Europe and increase awareness of the condition, the Task Force then performed an international survey. The aims of the survey were to provide basic data on numbers and characteristics of paediatric PCD patients in Europe, to describe age at diagnosis and to determine factors associated with delayed diagnosis. This should inform the European wide healthcare agenda for these patients.

\section{METHODS}

\section{Study design and population}

Using a two-stage design, we performed a cross-sectional questionnaire survey of all institutions (tertiary, secondary or primary care centres) considered likely to be treating paediatric PCD patients in Europe. With the help of the ERS membership roster, we aimed to identify in each country a national representative who distributed the questionnaires to all such centres. Thanks to repeated efforts, we found a national representative in most, but not all, countries in Europe. Turkey and Israel, who volunteered, were also included. Questionnaires were mailed between January 2007 and October 2008 and replies were collected until January 31, 2009. Depending on the national healthcare organisation, some representatives contacted only tertiary care centres while others included smaller institutions.

Data on total population counts for each participating country, stratified by 5-yr age groups, were obtained from the US Census Bureau International Data Base for 2007 [15]. Participating countries were grouped into five regions according to the United Nations (UN) definition of the European regions, with the following exceptions: The UK and Ireland were analysed as a separate region (British Isles); Estonia, Israel, Serbia and Turkey were grouped with Eastern Europe [16].

Data on general government expenditure on health (GGHE; the sum of outlays for health maintenance, restoration or enhancement paid for in cash or supplied in kind by government entities) were obtained from WHOSIS, the World Health Organization (WHO) Statistical Information System database bringing together core health statistics for the 193 WHO member states [17].

\section{Questionnaire}

The ERS Task Force developed a short questionnaire for national representatives, and a detailed questionnaire for clinical centres. National representatives reported the number of tertiary care paediatric centres in the country and listed all centres receiving a questionnaire. Tertiary care centres were defined as university hospitals or other tertiary referral centres, secondary care centres as regional referral centres with a respiratory unit and primary care centres as paediatric practices or small hospitals.

In a separate questionnaire, we asked each centre to supply a list of patients currently followed up, with dates of birth, dates of diagnosis, sex and information on situs inversus. For reasons of patient confidentiality, no identifying data were collected. To limit work for collaborating centres, no clinical details such as method of diagnosis or treatments, pedigrees or genetic data were collected at this stage.

\section{Analysis}

We double-entered all questionnaires into an EpiData database, eliminated double counts of cases reported by more than one centre, and analysed the data using Stata statistical software (version 10; STATA Corporation, College Station, TX, USA). Cases reported by both a tertiary care centre and a smaller centre were attributed to the tertiary care centre. To ensure comparability between countries, response rate was calculated as number of paediatric tertiary care centres replying/number of tertiary care centres existing in this country. The number of reported PCD cases in 5-yr age bands was compared to total population counts in the same age band.

For comparing numbers of diagnosed cases of PCD between countries, we concentrated on children aged 5-14 yrs at the time of the survey, because the upper age range of patients in paediatric care varied. For the other analyses, we included all patients aged $<20 \mathrm{yrs}$ at the time of the survey. The age at diagnosis was positively skewed; therefore, medians and geometric means are reported rather than means, and data were log-transformed for analysis. To determine risk factors for a delayed diagnosis, we used univariable and multivariable linear regression. All factors associated with the outcome $(p<0.05)$ and sex were retained in the multivariable model. In a sensitivity analysis, all computations were repeated for countries with a response rate $>60 \%$.

\section{RESULTS}

\section{Response rates and numbers of centres treating PCD patients}

We received 223 centre questionnaires from 26 countries (table 1). A list of patients was completed by 194 centres (141 tertiary and 53 secondary or primary care centres). Small centres often returned the questionnaire, filling in information on their diagnostic approaches for suspected PCD, but without adding a patient list, because they referred their PCD patients to a tertiary care centre for further care. From tertiary care centres, the overall response rate was 52\% (141 out of 272), varying between countries from $18 \%$ to $100 \%$. Clearly, in countries with a low response rate of tertiary care centres, the reported lists of patients do not represent the true prevalence of PCD in this country, and not even the number of diagnosed cases. However, in countries with a $100 \%$ response rate of tertiary care centres, the reported patients might be a fair estimate of paediatric patients diagnosed in this country. To facilitate interpretation of results, these are therefore reported stratified by country and sorted by response rates, with subtotals summarising results for countries with a high response rate. 


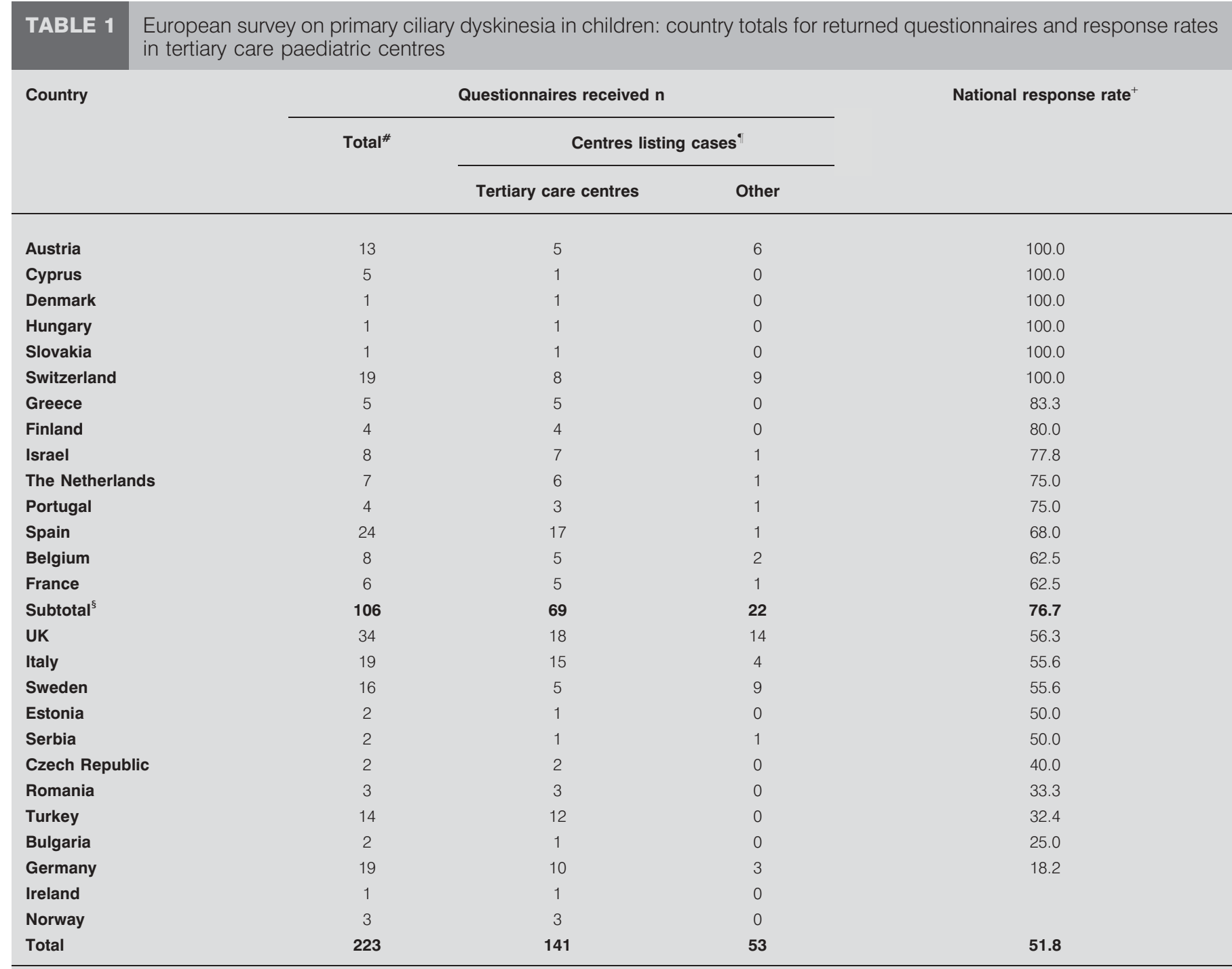

\#: all questionnaires that were returned completed; ${ }^{*}$ : all questionnaires that contained a list of patients; ${ }^{+}$: only refers to tertiary care centres and was calculated as the number of questionnaires returned by tertiary care paediatric centres, divided by the total number of tertiary care paediatric centres in the respective country; ${ }^{\S}$ : the subtotal summarises results for all countries with a response rate $>60 \%$.

\section{Numbers of doctor-diagnosed PCD patients per country}

The centres reported individual level data on 1,192 cases (table 2). Of these, 1,009 were aged $<20$ yrs at the time of the survey. Numbers of reported patients differed by age: at the time of the survey $161(16 \%)$ out of 1,009 patients were aged 0-4 yrs, 311 (31\%) 5-9 yrs, 320 (32\%) 10-14 yrs, and $217(21 \%)$ $15-19$ yrs. An additional 178 patients were aged $\geqslant 20$ yrs (fig. 1). For five children information on age was missing. In the 13 countries also distributing questionnaires to smaller centres, $15 \%$ of cases (108 out of 721 patients) came from nontertiary centres. The age distribution varied between countries, with more young patients reported from Austria, Germany and Italy, and older children from Hungary, Cyprus, Denmark and Sweden (fig. 2).

In order to estimate the prevalence of diagnosed PCD patients per country, we compared numbers of reported patients aged 5-14 yrs to numbers of inhabitants aged 5-14 yrs in each respective country. We found large international differences, with highest frequencies in Cyprus (111 cases per million inhabitants, equivalent to one in 10,000 children), Denmark (46 cases per million) and Switzerland (47 cases per million, both approximately one in 20,000 children; table 2 and fig. 3 ).

\section{Characteristics of diagnosed PCD patients}

Current age was reported for 1,187 cases and ranged from 0 to 68.5 yrs (fig. 1). Median (interquartile range (IQR)) age was 11.8 (7.3-16.8) yrs. There was a sex difference with 573 of 1,009 patients diagnosed at age $0-19$ yrs being males $(57 \%, 95 \%$ CI $54-60 \%$ ) and 430 females $(43 \%, 40-46 \%$; table 3 ).

Overall, 437 children (44\%, 95\% CI 41-47\%) had situs inversus (table 3). When excluding the outlier Spain (which reported only $10 \%$ with situs inversus) this proportion rose to $48 \%$ (427 out of 892). The proportion of patients with situs inversus was not associated with use of diagnostic tests (e.g. biopsy of 
TABLE 2 Number of reported cases and estimated prevalence of diagnosed primary ciliary dyskinesia in children

\begin{tabular}{|c|c|c|c|c|c|}
\hline \multirow[t]{2}{*}{ Country } & \multicolumn{3}{|c|}{ Patients reported" $\mathbf{n}$} & \multirow{2}{*}{$\frac{\text { Population count (2007) }}{5-14 \mathrm{yrs}}$} & \multirow{2}{*}{$\begin{array}{l}\text { Estimated prevalence of diagnosed cases per million } \\
\text { inhabitants aged } 5-14 \text { yrs }\end{array}$} \\
\hline & Total & $0-19$ yrs & $5-14$ yrs & & \\
\hline Austria & 47 & 36 & 21 & 871,751 & 24.1 \\
\hline Cyprus & 27 & 20 & 12 & 108,149 & 111.0 \\
\hline Denmark & 95 & 51 & 32 & 700,559 & 45.7 \\
\hline Switzerland & 65 & 62 & 40 & 844,638 & 47.4 \\
\hline Greece & 20 & 20 & 15 & $1,017,416$ & 14.7 \\
\hline Finland & 4 & 4 & 3 & 607,701 & 4.9 \\
\hline Israel & 87 & 62 & 31 & $1,261,179$ & 24.6 \\
\hline The Netherlands & 6 & 6 & 6 & $2,013,275$ & 3.0 \\
\hline Portugal & 7 & 6 & 6 & $1,178,035$ & 5.1 \\
\hline Subtotal & 653 & 527 & 340 & $23,022,182$ & 14.8 \\
\hline UK & 82 & 81 & 52 & $7,184,605$ & 7.2 \\
\hline Italy & 173 & 128 & 70 & $5,401,122$ & 13.0 \\
\hline Sweden & 49 & 48 & 26 & $1,007,512$ & 25.8 \\
\hline Estonia & 1 & 0 & 0 & 131,574 & 0.0 \\
\hline Serbia & 16 & 16 & 10 & $1,276,736$ & 7.8 \\
\hline Czech Republic & 13 & 13 & 4 & 974,518 & 4.1 \\
\hline Romania & 8 & 8 & 3 & $2,323,649$ & 1.3 \\
\hline Turkey & 105 & 102 & 65 & $12,090,479$ & 5.4 \\
\hline Bulgaria & & & & 670,619 & \\
\hline Germany & 63 & 58 & 39 & $7,995,913$ & 4.9 \\
\hline Ireland & & & & 562,709 & \\
\hline
\end{tabular}

\#: number of patients listed individually with date of birth and sex; ${ }^{\circ}$ : the subtotal summarises results for all countries with a response rate $>60 \%$.

ciliated epithelium $(p=0.08)$, ciliary beat frequency and pattern $(p=0.92)$, and electron microscopy $(p=0.22))$ in the respective countries, nor with number of reported cases $(p=0.96$; data not shown).

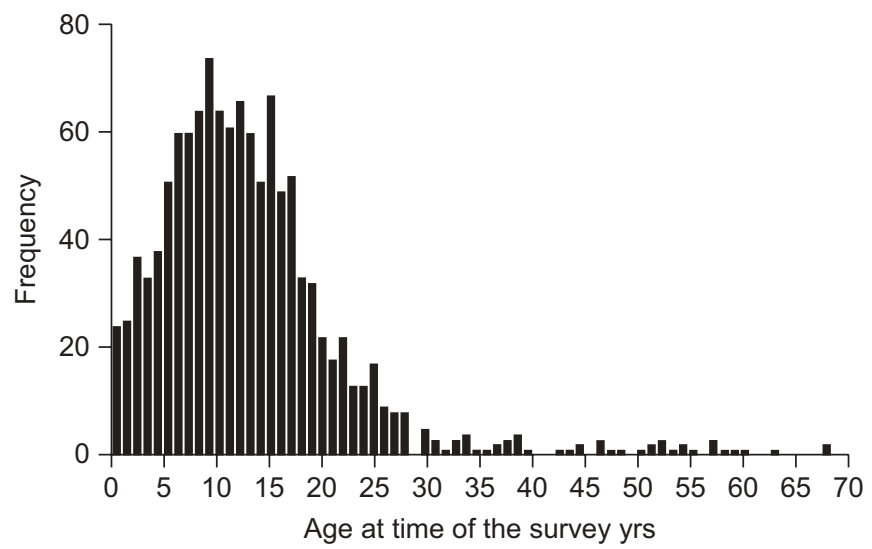

FIGURE 1. Age distribution at the time of the survey of all reported primary ciliary dyskinesia patients $(n=1,187)$.

\section{Age at diagnosis}

Age at diagnosis was reported for 1,051 patients. Of these, 473 $(45 \%)$ had been diagnosed at an age of $0-4$ yrs, $319(30 \%)$ aged 5-9 yrs, 155 (15\%) aged 10-14 yrs, 52 (5\%) aged 15-19 yrs, and $52(5 \%)$ aged $\geqslant 20$ yrs. Among these, 897 were currently aged under 20 yrs and included in further analyses. The distribution of age at diagnosis had two peaks: a first narrow and high peak between 0-2 yrs, mainly accounted for by children with situs inversus but also visible in those without (fig. $4 \mathrm{a}$ and $4 \mathrm{~b}$ ). This was followed by a second, broader peak extending from age 48 yrs, with a long tail thereafter. This second peak was more pronounced in children with situs solitus. Only 9\% (95\% CI 7$11 \%$ ) of children were diagnosed in the neonatal period, $16 \%$ (95\% CI $12-19 \%$ ) of those with situs inversus, and $4 \%$ (95\% CI $2-$ $6 \%)$ of those without $(\mathrm{p}<0.001)$.

Median age at diagnosis was 5.3 yrs (IQR 1.2-8.2, range 019 yrs), lower in children with situs inversus compared to those without ( 3.5 versus 5.8 yrs; $\mathrm{p}<0.001$ ), and in children treated in large centres ( $>20$ PCD patients) compared to smaller ones (4.1 versus 4.8 yrs; $\mathrm{p}=0.002$; table 4 ). Adjusting for current age, sex, situs inversus, and size of centre, the average age at diagnosis (geometric mean) was 5.0 yrs in Western Europe, 4.8 yrs in the 

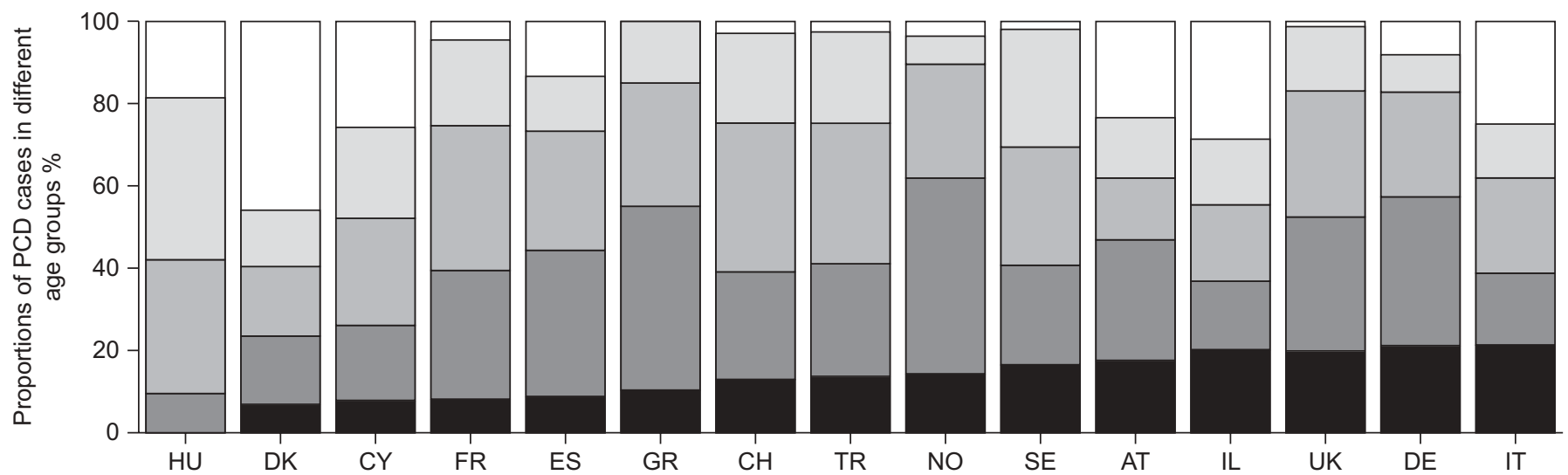

FIGURE 2. Proportions of primary ciliary dyskinesia (PCD) patients in different age groups, by country (countries with $>20$ reported PCD patients). AT: Austria; CH; Switzerland; CY: Cyprus; DE: Germany; DK: Denmark; ES: Spain; FR: France; GR: Greece; HU: Hungary; IL: Israel; IT: Italy; NO: Norway; SE: Sweden; TR: Turkey. $\mathbf{a}: 0-$ $4 \mathrm{yrs} ; \square:$ 5-9 yrs; $\square:$ 10-14 yrs; $\square: 14-19 \mathrm{yrs} ; \square: \geqslant 20 \mathrm{yrs}$.

British Isles, $6.5 \mathrm{yrs}$ in Southern Europe, $5.5 \mathrm{yrs}$ in Northern Europe and $6.8 \mathrm{yrs}$ in Eastern Europe $(p<0.001$; table 4$)$. Results were similar when the analysis was repeated for countries with a response rate $>60 \%$ (table E1 in the online supplementary material). Adjusted age at diagnosis for individual countries is shown in figure E1 in the online supplementary material.

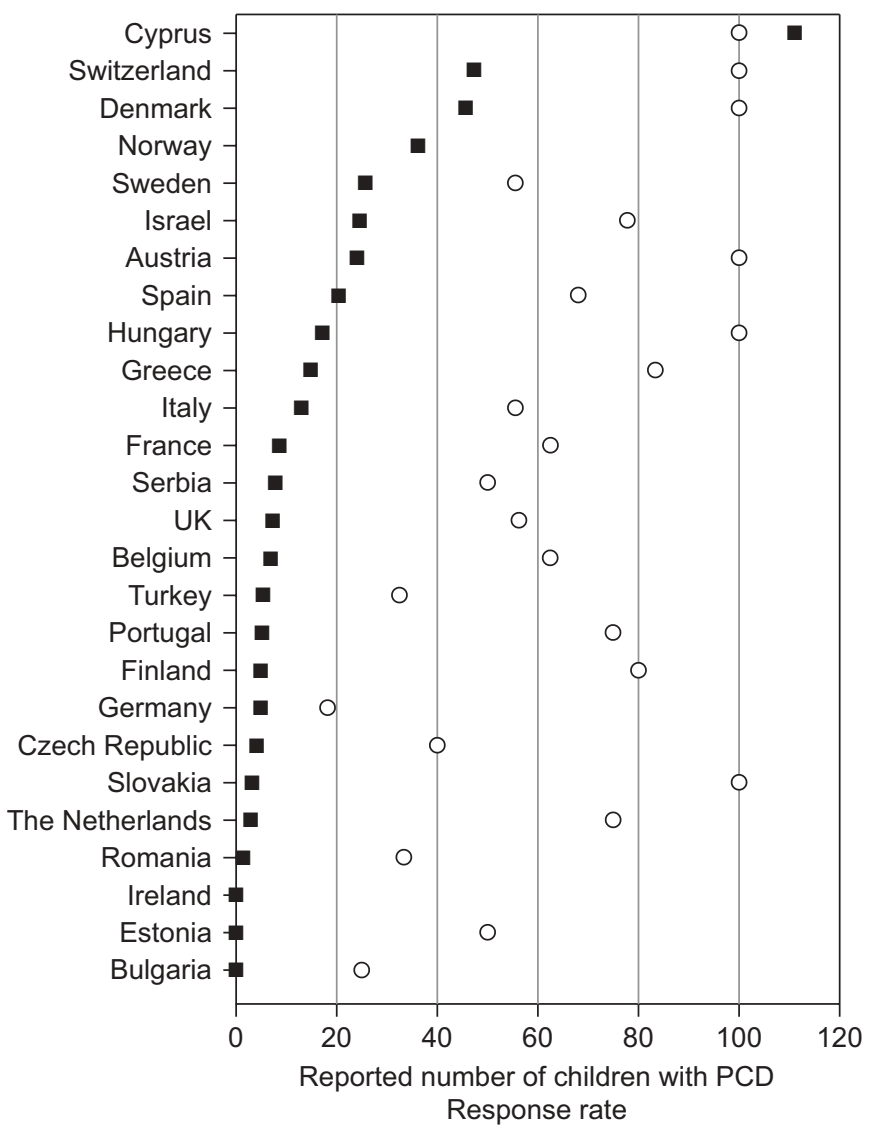

FIGURE 3. Reported number of children with primary ciliary dyskinesia (PCD) aged 5-14 yrs ( $\mathbf{\square})$ at time of the survey, per million inhabitants aged 5-14 yrs, by country. $\bigcirc$ : response rate.
Mean age at diagnosis in different countries was strongly correlated with GGHE in the respective country (fig. $5 \mathrm{a}$ ): a 1,000 USD increase in GGHE was associated with a $0.60 \mathrm{yrs}$ decrease in age of diagnosis (95\% CI $0.55-0.65 ; \mathrm{p}<0.001$ ). Similarly, the prevalence of diagnosed cases was correlated with GGHE (fig. 5b), with an increase of 5.23 (95\% CI 4.62-5.84; $\mathrm{p}<0.001$ ) diagnosed cases per million inhabitants aged 514 yrs per 1,000 USD increase in GGHE. Again, results were similar for countries with a response rate $>60 \%$. Inclusion of the outlier Cyprus changed the estimate to 3.11 (95\% CI $2.14-$ 4.10; $\mathrm{p}<0.001$ ) diagnosed patients per million inhabitants per 1,000 USD increase (fig. E2b in the online supplementary material). In Cyprus, age at diagnosis was mainly defined by the starting date of a paediatric respiratory clinic, which actively searched for cases. There was no correlation between mean age at diagnosis in a country and estimated prevalence of PCD (rho $=-0.018, p=0.59)$, suggesting again that our findings for age at diagnosis were not affected by response rates to the survey.

\section{DISCUSSION}

This paper presents the largest international survey of paediatric PCD patients ever undertaken, and includes data from 1,192 patients from 26 European countries. In countries with a good response rate, prevalence of diagnosed cases in 5 $14 \mathrm{yr}$ olds was between one in 10,000 and one in 20,000. Median age at diagnosis was $5.0 \mathrm{yrs}$, lower in those with situs inversus and in children treated in large centres, and varied significantly between regions. Both number of diagnosed cases and median age at diagnosis were strongly correlated with the general GGHE.

\section{Strengths and limitations}

This is the first study assessing numbers of doctor-diagnosed PCD cases in children in an international survey with a uniform methodology. Only one study exists where the same diagnostic methodology was used to determine the prevalence of PCD in a well defined population. This showed a very high incidence of one in 2,200 in a British Asian population that may have been due to high levels of consanguinity [13]. Other approaches were limited to single countries [10] or specific populations, such as atom bomb survivors [11], or used 
TABLE 3 Characteristics of diagnosed primary ciliary dyskinesia patients aged 0-19 yrs at time of the survey

\begin{tabular}{|c|c|c|c|c|c|}
\hline \multirow[t]{2}{*}{ Country } & \multirow[t]{2}{*}{ Total ${ }^{\#} \mathbf{n}$} & \multirow[t]{2}{*}{ Female sex $\%(95 \% \mathrm{Cl})$} & \multirow[t]{2}{*}{ Situs inversus \% $(95 \% \mathrm{Cl})$} & \multicolumn{2}{|c|}{ Age at diagnosis ${ }^{\#}$ yrs } \\
\hline & & & & Total $n$ & Median (IQR) \\
\hline Austria & 36 & $42(25-59)$ & $53(36-70)$ & 28 & $4.8(0.3-8.2)$ \\
\hline Cyprus & 20 & $40(16-64)$ & $45(21-69)$ & 19 & $10.1(7.0-13.9)$ \\
\hline Denmark & 51 & $45(31-59)$ & 35 (22-49) & 51 & $4.1(0.8-7.9)$ \\
\hline Switzerland & 61 & $39(27-52)$ & $56(43-69)$ & 49 & $3.8(1.0-6.7)$ \\
\hline Greece & 20 & $55(31-79)$ & $50(26-74)$ & 20 & $4.6(2.0-7.5)$ \\
\hline Finland & 4 & $75(0-100)$ & $50(0-100)$ & 4 & $3.7(1.7-5.0)$ \\
\hline Israel & 61 & $41(28-54)$ & $57(44-70)$ & 56 & $1.9(0.2-6.5)$ \\
\hline The Netherlands & 6 & $50(0-100)$ & $50(0-100)$ & 6 & $1.9(0.5-4.7)$ \\
\hline Portugal & 6 & $33(0-88)$ & $83(40-100)$ & 6 & $6.1(0.5-12.3)$ \\
\hline Subtotal & 525 & $44(40-48)$ & $40(35-44)$ & 489 & $5.0(1.2-7.5)$ \\
\hline UK & 80 & $43(31-54)$ & $45(34-56)$ & 53 & $3.2(0.7-5.2)$ \\
\hline Italy & 128 & $41(33-50)$ & $46(38-55)$ & 127 & $4.7(0.7-8.2)$ \\
\hline Sweden & 46 & 35 (20-49) & $29(16-43)$ & 43 & $6.4(1.5-10.2)$ \\
\hline Serbia & 16 & $25(1-49)$ & $31(6-57)$ & 16 & $8.3(2.3-12.4)$ \\
\hline Czech Republic & 13 & 54 (22-85) & $45(10-81)$ & 13 & $5.1(3.9-11.2)$ \\
\hline Romania & 8 & $75(36-100)$ & $88(58-100)$ & 8 & $1.1(0.3-8.0)$ \\
\hline Turkey & 102 & $46(36-56)$ & $71(62-80)$ & 102 & $7.3(3.7-10.5)$ \\
\hline Germany & 57 & $33(21-46)$ & $46(33-60)$ & 38 & $5.0(1.4-8.6)$ \\
\hline Norway & 28 & 43 (23-62) & $32(14-51)$ & 9 & $5.2(3.2-6.9)$ \\
\hline Total & 1,003 & $43(40-46)$ & $44(41-47)$ & 897 & $5.3(1.2-8.2)$ \\
\hline
\end{tabular}

$\mathrm{n}=1,009$. *: date of diagnosis, sex, or information on situs inversus were missing for some patients; " rate of $>60 \%$. IQR: interquartile range.

approximation methods based on radiologically confirmed bronchiectasis [12]. Our approach has its own limitations: response rates varied between countries, diagnostic criteria differed, some centres did not list all patients, only paediatricians were approached and undiagnosed patients could obviously not be included. Age at diagnosis was missing for $11 \%$ of patients. A few countries did not participate. For these reasons results were stratified by country and compared to national response rates.

To keep the workload for participating centres manageable we collected only limited information on individual patients. Therefore, our data essentially represent "doctor-diagnosed PCD" and we cannot be certain if individual patients had been diagnosed according to current diagnostic standards (ciliary beat frequency and pattern, electron microscopy, cell culture and other specific tests) [1], or mainly on clinical grounds (symptoms, bronchiectasis and situs inversus). Hence, some of the cases reported in this survey might not suffer from PCD. For example, only a proportion of patients with situs inversus have PCD and we are aware of a number of patients diagnosed initially on clinical grounds with PCD whose diagnosis had to be revised when appropriate diagnostic tests were conducted. However, 94\% of centres reporting patients had electron microscopy or ciliary function tests available, and excluding the other $6 \%$ in a sensitivity analysis did not change any of the main results. It would have been ideal to narrow this down further by only including data from centres which assessed both function (ciliary beat frequency and pattern) and structure (transmission electron microscopy), but this would have reduced the sample size greatly. All the countries with high prevalence estimates (Cyprus, Denmark, Switzerland) have facilities for a detailed work-up. In Switzerland, every PCD patient must be biopsied for coverage of medical costs by the insurance for birth defects. In Cyprus and Denmark, all PCD patients were diagnosed in an experienced single national reference centre employing up-to-date diagnostic methods.

\section{Numbers of diagnosed cases per country}

The reported numbers of children with doctor-diagnosed PCD varied widely between countries. Bearing in mind the differences in prevalence of cystic fibrosis across Europe, it is not impossible that part of this variability reflects true differences in disease incidence, e.g. underlying geographic differences in mutational data, founder effects for certain gene mutations or differing proportions of couples with consanguineous marriages [18]. Unfortunately, ethnicity and country of origin for immigrant patients could not be assessed in this survey. However, we believe that varying response rates and 

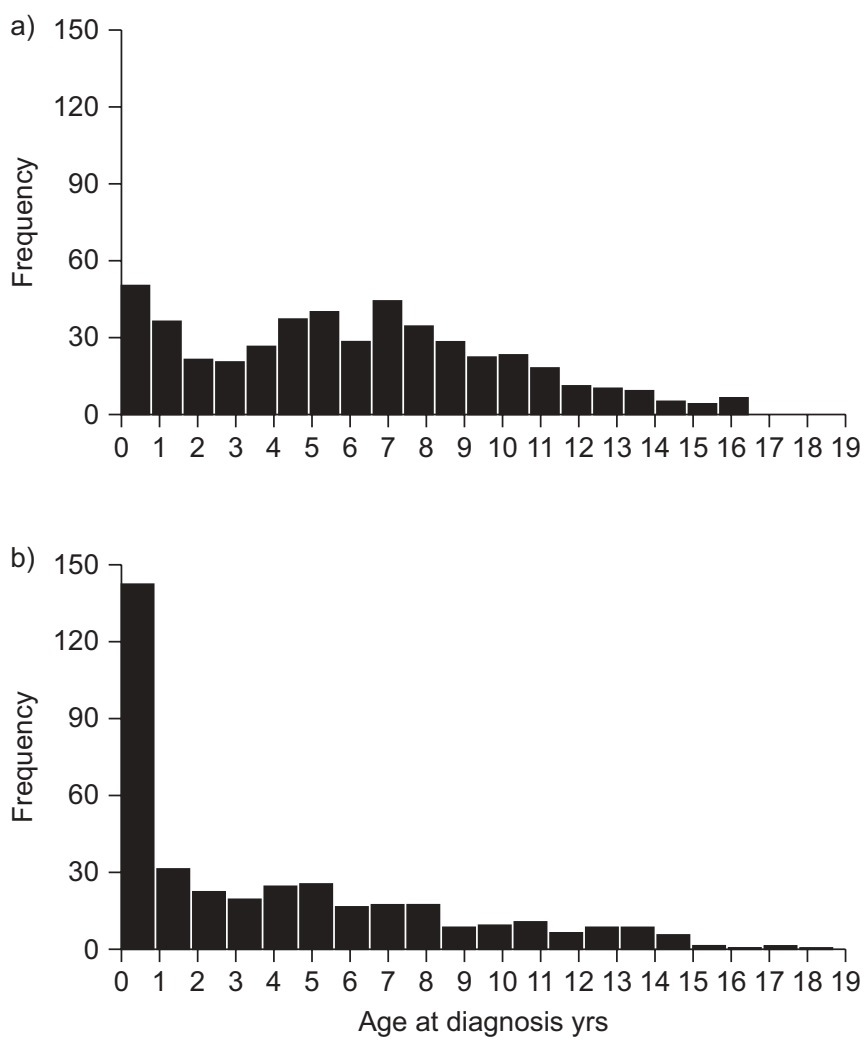

FIGURE 4. Distribution of age at diagnosis of primary ciliary dyskinesia patients aged 0-19 yrs at time of the survey, by a) situs solitus or b) situs inversus $(n=897)$.

differences in awareness and diagnostic work-up of PCD between participating countries are by far the most important factors explaining differences in reported numbers of patients and in prevalence estimates.

In several large countries (France, Italy, Germany and the UK) response rates of tertiary care paediatric hospitals were low and, sometimes (e.g. the Netherlands, Slovakia and the UK), participating centres reported only a fraction of their patients. Also, patients treated by adult pulmonologists or ear, nose and throat physicians might have been missed. For an approximation of the prevalence of diagnosed PCD in children, we have to rely, therefore, on data from countries with high response rates, mainly those treating all patients in national reference centres (Cyprus and Denmark) and small countries with few and closely collaborating paediatric pulmonologists (Austria and Switzerland).

As the methods of diagnosis were not ascertained for individual patients, it is possible that PCD was over- or under-diagnosed in some places. Over-diagnosis could be suspected in countries with a low proportion of children with situs inversus. Our results do not support this. Overall, there was no correlation between the proportion with situs inversus in a country and the prevalence of diagnosed cases $(p=0.96)$, and countries with a high prevalence often reported a high proportion of situs inversus (Switzerland: 56\%; Austria: 53\%; and Cyprus: $45 \%$ ). Under-diagnosis is probably more of an issue.
For instance, a PCD variant caused by recessive DNAH11 mutations is characterised only by a subtle alteration of the ciliary beat recognisable only by high-speed videomicroscopy, without ultrastructural axonemal defects. Most of these cases will have been missed in our study, because only few centres used high-speed videomicroscopy analyses [7, 19, 20].

Balancing all these factors, and considering that there are probably undiagnosed children with minor symptoms, we believe that the often cited prevalence estimates of one in 30,000 to one in 40,000 are too low $[10,12]$. All countries in our survey with higher estimates (Cyprus (one in 10,000), Denmark and Switzerland (both one in 20,000)) use a thorough diagnostic work-up based on nasal/bronchial biopsies, electron microscopy and ciliary beat analysis, and well-organised care in one or few specialised centres, making over-diagnosis unlikely. Clearly, comprehensive national PCD registries that record baseline and follow-up data on all cases diagnosed in a country are needed to derive more valid prevalence estimates.

\section{Characteristics of reported patients}

Numbers of reported patients per age group increased with age from infancy to age $8-10$ yrs, and decreased thereafter (fig. 1). While the increase in early childhood is probably explained by delays in diagnosis, the decreasing numbers of older children might reflect early transition into adult care or improved diagnosis in more recent cohorts of children, or both.

Situs inversus was reported in $48 \%(45-51 \%)$ of patients (excluding Spain). This proportion is slightly lower than 50\%, which might be explained by the fact that central microtubular defects, responsible for some PCD cases, are not associated with situs inversus. In fact, our results are identical to those reported by KENNEDY et al. [21] in a large sample of patients worked up in great detail (47.7\% with situs inversus), implying that overall, the quality of diagnosis in our survey might be satisfactory.

The sex distribution was unequal, with a higher proportion of boys $(57 \%$, 95\% CI $54-60 \%)$ in all age groups. We can only speculate on the underlying causes: boys might have a more typical disease presentation due to their known proneness to respiratory infections [22], or girls might be under-diagnosed compared to boys even when presenting with similar symptoms, the so-called Yentl syndrome [23]. Perhaps $X$ chromosomal recessively inherited PCD variants may also contribute to the unequal sex distribution. This has been shown for X-linked syndromic PCD variants caused by RPGR (PCD plus retinitis pigmentosa) and OFD1 (PCD plus mental retardation) mutations that are responsible for $\mathrm{PCD}$ variants associated with retinitis pigmentosa [24-26]. It is possible that, other non-syndromic PCD variants are also caused by mutations of genes located on the $\mathrm{X}$ chromosome.

\section{Age at diagnosis}

As previously reported, age at diagnosis was nearly twice as high in children with situs solitus [9]. Although, more PCD cases were reported among males overall, age at diagnosis did not vary by sex.

Size of the treating centre was strongly associated with age at diagnosis. Children were diagnosed at a younger age in centres caring for $>20$ PCD patients compared to smaller centres (4.1 versus 4.8 yrs; $\mathrm{p}=0.002$ ). This suggests that, analogous to 
TABLE 4 Determinants of age at diagnosis of primary ciliary dyskinesia (PCD) patients aged 0-19 yrs at time of the survey

\begin{tabular}{|c|c|c|c|c|c|}
\hline & \multirow[t]{2}{*}{ Patients $\mathrm{n}$} & \multicolumn{2}{|c|}{ Unadjusted } & \multicolumn{2}{|c|}{ Adjusted $^{\#}$} \\
\hline & & Geometric mean yrs & p-value & Geometric mean yrs & $p$-value \\
\hline \multicolumn{6}{|l|}{ Sex } \\
\hline Male & 510 & 4.56 & 0.316 & 4.97 & 0.581 \\
\hline Female & 383 & 4.83 & & 5.09 & \\
\hline Situs inversus & 389 & 3.50 & & 3.40 & \\
\hline \multicolumn{6}{|l|}{ Type of centre } \\
\hline Tertiary & 797 & 4.68 & 0.707 & & \\
\hline Secondary or primary & 100 & 4.52 & & & \\
\hline \multicolumn{6}{|l|}{ PCD patients cared for $n$} \\
\hline $1-10$ & 368 & 4.79 & 0.002 & 4.97 & $<0.001$ \\
\hline Western & 232 & 4.03 & 0.001 & 4.97 & $<0.001$ \\
\hline British Isles & 53 & 3.50 & 0.260 & 4.75 & 0.641 \\
\hline Southern & 268 & 5.05 & 0.002 & 6.45 & $<0.001$ \\
\hline Northern & 107 & 4.63 & 0.150 & 5.51 & 0.164 \\
\hline Eastern & 237 & 5.26 & $<0.001$ & 6.80 & $<0.001$ \\
\hline
\end{tabular}

European regions are as follows: Western Europe: Austria, Belgium, France, Germany, the Netherlands, Switzerland; British Isles: Ireland, UK; Southern Europe: Cyprus, Greece, Italy, Portugal, Spain; Northern Europe: Denmark, Finland, Norway, Sweden; Eastern Europe: Bulgaria, Czech Republic, Estonia, Hungary, Israel, Romania Serbia, Slovakia, Turkey. $\mathrm{n}=897$. " : adjusted for sex, current age, situs inversus, number of PCD patients cared for and European region. Age at diagnosis at baseline (male, situs solitus, 1-10 PCD patients cared for, average current age (10.4 yrs), Western Europe) was $4.97 \mathrm{yrs.} \mathrm{"}$ : sex or situs were missing for some patients.

cystic fibrosis, it might be advisable to centralise care for PCD patients in a few highly specialised centres. Therefore, it is of concern that in many countries, PCD patients were treated by a large number of centres. For instance in Switzerland 65 patients were reported by 17 centres ( 8 tertiary care, 9 others). Similarly, in the UK, patients were reported by 32 centres (18 tertiary, 14 others).

Adjusting for current age, sex and situs inversus, we found considerable international differences in age at diagnosis, with earlier diagnosis in the British Isles, Northern and Western Europe, compared to Southern and Eastern Europe. This was partly explained by differences in the GGHE, with a 0.6 yrs decrease in age at diagnosis for every 1,000 USD increase in GGHE.

\section{Implications and conclusions}

Little is known on the impact of a delayed or missed diagnosis on patients. Adult patients have a high burden of chronic
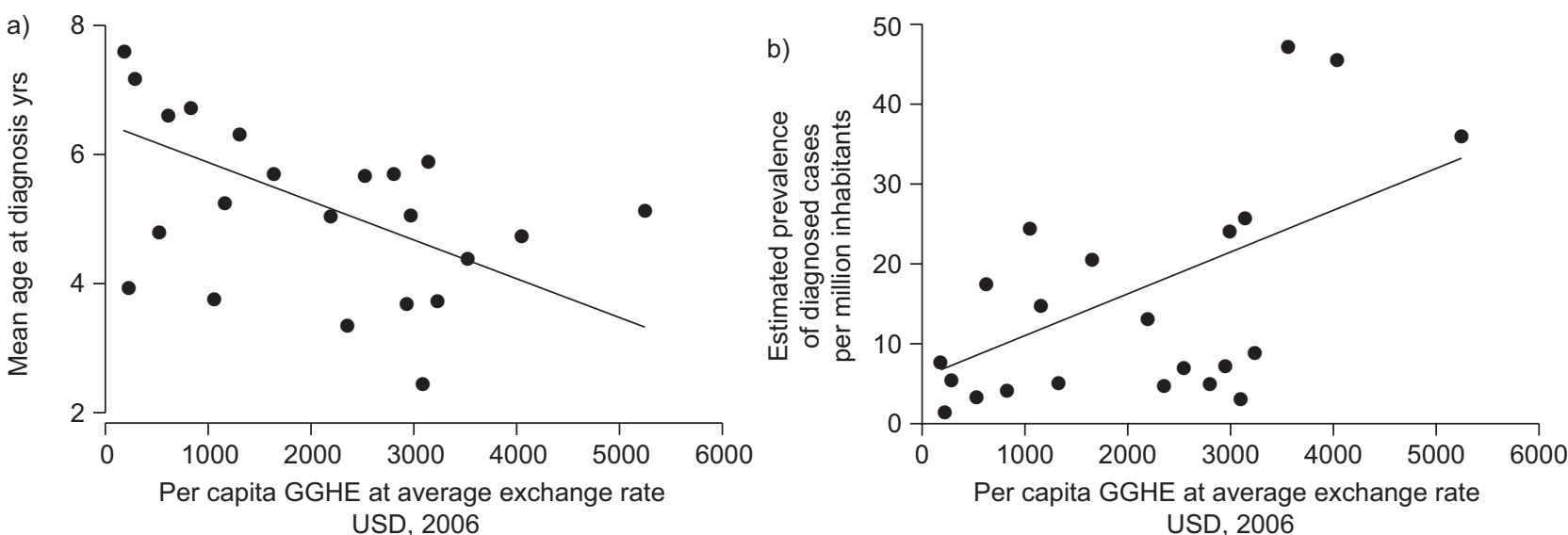

FIGURE 5. Association between the general government expenditure on health (GGHE) in the country and a) mean age at diagnosis of primary ciliary dyskinesia patients aged 0-19 yrs at the time of the survey and b) prevalence of diagnosed patients per million inhabitants aged 5-14 yrs (excluding Cyprus; $n=25$ ). 
respiratory morbidity [4]. Several studies showed reduced lung function in older patients [27, 28]. It has been reported that lung function may be stabilised after diagnosis and appropriate management, suggesting a positive effect of early diagnosis and appropriate respiratory management on longterm outcome of PCD patients [4, 27]. However, this was not confirmed in a recent analysis of data from Denmark, and further large prospective studies are needed [28]. The next step in this collaboration will be to extend our database and use it as a starting point for an international study, collecting detailed information on diagnosis, clinical presentation and measurements in a representative sample of patients, with the objective of describing morbidity and burden of disease in paediatric PCD, particularly signs of irreversible damage (such as bronchiectasis). Comparison of children diagnosed early to those diagnosed at a later age will allow the estimation of the economic burden of delayed diagnosis. For cystic fibrosis it has been shown that early diagnosis by newborn screening saves money by reducing the costs of treatment [29]; we speculate that this might also apply to PCD. Long-term prospective follow-up of these patients will allow assessment of prognosis and response to treatments. Finally, the use of appropriate databases will allow the performance of randomised controlled trials of treatment. As recently highlighted in a European consensus statement [14], an evidence base for the treatment of PCD is still lacking.

In conclusion, this study strongly suggests that PCD occurs more frequently than generally thought, but is under-diagnosed and diagnosed late in many European countries. Prerequisites for improving diagnostic rates include a greater clinical awareness of the condition. Indications for testing for PCD include: children with situs inversus or heterotaxy, children with chronic productive cough or bronchiectasis of unknown cause or severe upper respiratory morbidity, children with cerebral ventriculomegaly, siblings of patients, babies with unexplained neonatal respiratory distress, males with immotile sperm and females with recurrent ectopic pregnancy [14]. Diagnostic testing for PCD and interpretation of results are difficult and involve ciliary beat pattern and frequency analysis using video recording and electron microscopy as key techniques, accompanied in some cases by genetic testing. Sometimes repeated brush samples and culture of ciliary brushings are necessary [14]. Our study strongly suggests that centralised evaluation and treatment of children with PCD at one or few respiratory reference centres in each country is associated with more and earlier diagnoses, and highlights the inequalities in the diagnosis of PCD across Europe. These inequalities are partly explained by insufficient government funding for health and might be an appropriate subject for the European Union to address.

\section{SUPPORT STATEMENT}

The European Respiratory Society has financially supported meetings of the PCD Task Force. C.E. Kuehni and M-P.F. Strippoli were funded by the Swiss National Science Foundation (PROSPER grants 3233069348 and 3200-069349). H. Omran was funded by the Deutsche Forschungsgemeinschaft DFG Om 6/4.

\section{STATEMENT OF INTEREST}

None declared.

\section{ACKNOWLEDGEMENTS}

The collaborating members of the ERS Task Force on primary ciliary dyskinesia in children are as follows. I. Azevedo (Dept of Paediatrics, Hospital São João, Oporto, Portugal); G. Baktai (Paediatric Institute Svabhegy, Budapest, Hungary); A. Barbato (Dept of Paediatrics, University of Padova, Padova, Italy); J. de Blic (Dept of PneumoAllergology, Necker-Enfants Malades Hospital, Paris, France); A. Bush (Royal Brompton Hospital, London, UK); C. O'Callaghan (Division of Paediatrics, Dept of Infection, Immunity and Inflammation, University of Leicester and Leicester Children's Hospital, Leicester, UK); K-H. Carlsen (Voksentoppen BKL, Rikshospitalet University Hospital, Oslo, Norway); L. Larisa Dracea (Sectia Afectiuni Resporatorii, Spitql de Copii, Brasov, Romania); E. Eber (Dept of Paediatrics and Adolescent Medicine, Medical University of Graz, Graz, Austria); S. Elborn (Respiratory Medicine Group, Centre for Infection and Immunity, Queen's University of Belfast, Belfast, Ireland); A. Escribano (University Clinic Hospital, University of Valencia, Valencia, Spain); T. Frischer (Universitätskilnik für Kinder und Jugendheikunde, Vienna, Austria); E. Haarman (Dept of Paediatrics and Neonatology, Emma Children's Hospital Academic Medical Centre, Amsterdam, the Netherlands); B. Hesselmar (Dept of Paediatrics, Institute of Clinical Sciences, Sahlgrenska Academy of Gothenburg University, Gothenburg, Sweden); C. Hogg (Royal Brompton Hospital, London, UK); M. Jorissen (Ear, Nose and Throat Dept, Head and Neck Surgery, University Hospitals Leuven, Leuven, Belgium); B. Karadag (Division of Paediatric Pulmonology, Marmara University, Istanbul, Turkey); C.E. Kuehni (Institute of Social and Preventive Medicine (ISPM), University of Berne, Berne, Switzerland); M. Korppi (Paediatric Research Centre, Tampere University and University Hospital, Tampere, Finland); J. Lucas (Division of Infection, Inflammation and Immunity, University of Southampton School of medicine, Southampton, UK); E. Maurer (Institute of Social and preventive Medicine (ISPM), University of Berne, Berne, Switzerland); P. Minic (Mother and Child Health Institute of Serbia "Dr Vukan Cupic", Belgrade, Serbia and Montenegro); H. Mussaffi (Cystic Fibrosis Service, Pulmonary Institute, Schneider Children's Medical Centre of Israel, Petah-Tikva, Israel); K.G. Nielsen (Danish Paediatric Pulmonary Service, Rigshospitalet, Copenhagen, Denmark); H. Omran (Klinik und Poliklinik für Allgemeindepaediatrie, University Hospital, Munster, Germany); P. Pohunek (Dept of Paediatrics, University Hospital Motol and $2^{\text {nd }}$ School of Medicine, Charles University, Prague, Czech Republic); K. Priftis (Dept of Allergy-Pneumonology, Penteli Children's Hospital, Palea Penteli, Athens, Greece); M-A. Riikjärv (Tallinn Children's Hospital, Tallinn, Estonia); G. Petrova Stoyanova (Paediatric Clinic, Sofia, Bulgaria); V. Pohanka (Srobars Institute for TB and Respiratory disease, Dolný Smokovec, Slovakia); D. Snijders (Dept of Paediatrics, University of Padova, Padova, Italy); M-P.F. Strippoli (Institute of Social and Preventive Medicine (ISPM), University of Berne, Berne, Switzerland); T. Svobodovà (Dept of Paediatrics, University Hospital Motol, Prague, Czech Republic); P. Yiallouros (Cyprus International Institute for Environmental and Public Health, Cyprus University of Technology, Limassol, Cyprus); Z. Zivkovic (Centre for Lung Diseases and TB, Children Medical Centre "Dr Dragisa Misovic", Belgrade, Serbia).

The authors and all the members of the ERS Task Force would like to thank all centres participating in the primary ciliary dyskinesia survey. Austria: Kardinal Schwarzenberg'sches Krankenhaus (Schwarzach), SMZ Ost Donauspital (Vienna), University Childrens Hospital (Graz), St. Anna Kinderspital (Vienna), a.ö. Landeskrankenhaus (St. Pölten), Klinikum Kreuzschwestern (Wels), Wilhelminenspital (Vienna), University Childrens Hospital (Vienna), LKH (Feldkirch), Medical University (Innsbruck), a.ö. LKH des Landes Kärnten (Klagenfurt), Landeskinder- und Frauenklinik (Linz), Paracelsus Medizinische Privatuniversität - Childrens Hospital (Salzburg); Belgium: Virge Jesse Ziekenhui (Hasselt); UZ (Leuven); UCL Mont-Godinne (Yvoir), Clinique Universitaire Saint-Luc (Brussels); AZ-VUB Jette (Brussels); 
UZ (Ghent); CHC St-Vincent (Rocourt); AT Middelheim Kon. Paola Kinderziekenhuis (Antwerp); British Isles: Our Ladys Childrens Hospital (Dublin); St James University Hospital (Leeds), Striling Royal Infirmary (Fife), Royal Devon and Exeter Foundations NHS Trust (Devon), Royal Aberdeen Children's Hospital (Aberdeen); Royal Brompton Hospital (London), Addenbrookes NHS Trust (Cambridge), Freeman Hospital (Newcastle Upon Tyne), Royal Infirmary (Leicester), Ninewells Hospital (Dundee), Nottingham City Hospital (Nottingham), Royal Blackburn Hospital (Blackburn), Swansea NHS Trust (Swansea), Kings Mill Hospital (Sutton in Ashfield), Goodhope Hospital (Sutton Coldfield), Glan Clwyd Hospital (Rhyl), Southampton University Hospital NHS Trust (Southampton), Royal Belfast Hospital Sick Children (Belfast), Huddersfield Royal Infirmary (Huddersfield), West Wales Hospital (Carmather), Teaching Hospitals Foundation Trust (Bradford), Children's Hospital for Wales (Cardiff), York Foundation NHS Trust (York), Royal Hospital for Sick Children (Edinburgh), Children's Hospital (Bristol), Shrewsbury and Telford Hospital NHS Trust (Shrewsbury), Children's Hospital (Birmingham), Children's University Hospital NHS Trust (Manchester), Royal Cornwell Hospital Trust (Truro), Derriford Hospital (Plymouth), Children's Hospital (Oxford), Royal Victoria Infirmary (Newcastle), Royal Alexandra Children's Hospital (Brighton), University Hospital (Cork), South Devon Healthcare Trust (Devon); Bulgaria: University Hospital Alexendrovska (Sofia); University Hospital (Pleven); Cyprus: General Hospital (Larnaca), Archbishop Makarios Hospital (Nicosia), New Famagusta General Hospital (Paralimni-Famagusta), General Hospital (Paphos), General Hospital (Limassol); Czech Republic: Teaching Hospital of Palacky University (Olomouc), University Hospital Motol (Prague); Denmark: University Hospital, Paediatric Pulmonary Service and Ciliary Lab (Copenhagen); Estonia: Children's Hospital (Tallinn), Univesity Children's Clinic (Tartu); Finland: University Hospital (Tampere), University Hospital (Oulu), University Hospital (Kuopio), University Hospital (Helsinki); France: Armand Trousseau Hospital (Paris), Hôpital Necker Enfants Malades (Paris), Centre Hospitalier Intercommunal (Créteil), Hôpital des Enfants CHU (Toulouse), Hôpital Debrousse (Lyon), Hôpital Jeanne de Flandres (Lille); Germany: Kinder-und Jugendklinik (Erlangen), University Children's Hospital Charite (Berlin), University Hospital (Freiburg), Universitätsklinik für Kinder-und Jugendmedizin (Tübingen), Praxis für Kinderpneumologie und Allergologie (Mannheim), Klinikum des Universität (Munich), Kinderpneumologie (Eckental), Universitätsklinik (Düsseldorf), Akad. Lehrkrankenhaus der J. Gutenberg - Universität Mainz (Worms), Evangelisches Krankenhaus (Bielefeld), Marien-Hospital (Wesel), Klinik für Kinder-und Jugendmedizin (Eberswalde), Klinikum (Augsburg), Kinderarztpraxis Laurensberg (Aachen), Universitätsklinikum Schleswig Holstein Campus (Kiel), Universitäts-Kinderklinik (Bochum), Childrens University Hospital (Cologne), Josefinum (Augsburg), Altonaer Kinderkrankenhaus (Hamburg); University Medical Center (Hamburg); Margaritenhospital (Schwaebisch Gmuend); Deutsche klinik fuer diagnostic (Wiesbaden); Zentrum fuer Kinderheilkunde und Jugendmedizin (Gießen); Greece: Athens Medical Centre (Athens), Penteli Children's Hospital (Athens), University Hospital (Patra), University (Thessaloniki), University Hospital of Crete (Heraklion); Hungary: Paediatric Insitute-Svabhegy (Budapest); Israel: Ziv Medical Centre (Sefad), Dana Children Hospital, Tel-Aviv Medical Centre (Tel-Aviv), Safra Children's Hospital, Sheba Medical Centre (Ramat-Gan), Shaare Zedek Medical Centre (Jerusalem), Rambam Medical Centre (Haifa), Hadassah Mt Scopus University Medical Centre (Jerusalem), Soroka Medical Centre (Beer-Sheva), Schneider Children's Medical Centre of Israel (Petah-Tikva); Italy: Paediatric Department University Bari, Ospedale Infantile Burlo Garofolo - Clinica Paediatrica (Trieste), Ospedale Macedonio Melloni (Milan), Paediatric Unit-General Hospital (Bolzano), UO di Fibrosi Cistica-Clinica Paediatrica (Parma), Centro di Supporto per la Fibrosi Cistica (Brescia), Institute of
Respiratory Diseases (Milan), Paediatric Department-Federico II University (Naples), Azienda di Rilievo Nazionale e di Alta Specializzazione-ARNAS (Palermo), Anna Meyer Children's Hospital (Florence), Azienda Ospedaliera "Fate Bene Fratelli" (Milan), Clinica Paediatrica Università di Catania, Paediatric Department University Udine, Instituto "G. Gaslini" (Genoa), Paediatric Department University Padova (Padova), Paediatric Department University Pisa (Pisa), Ospedale Paediatrico Bambino Gesù (Rome), Cystic Fibrosis Centre (Verona), Clinica Paediatrica (Ancona); the Netherlands: VU University Medical Centre (Amsterdam), University Medical Centre (Maastricht), Amphia Ziekenhuis (Breda), University Medical Centre (Utrecht), Radbout University Medical Centre (Nijmegen), Sofia Children's Hospital - Erasmus MC (Rotterdam); Norway: Voksentoppen (Oslo), Ulleval University Hospital (Oslo), St Olavs Hospital (Trondheim); Portugal: Hospital de Nossa Senhora do Rosário (Barreiro), Hospital Pediátrico (Coimbra), Hospital de S. João (Oporto), Hospital de Santa Maria (Lisbon); Romania: University Children's Hospital (Brasov), Childrens' University Hospital Alfred Rusescu (Bucharest), Emergency Children's Hospital G. Alexandrescu (Bucharest); Serbia: Centre for Paediatric Pulmonology and TB, Medical Center "Dr Dragisa Misovic" (Belgrade), Institute for Mother and Child Health Care (Belgrade); Spain: Hospital de Jerez (Jerez de la Frontera), Corporacio Sanitaria Parc Tauli (Sabadell-Barcelona), Hospital Infantil La Paz (Madrid), Hospital Clínico Universitario (Valencia), Hospital Universitario de Valme (Seville), Hospital Universitario Virgen de la Arrixaca (Murcia), Hospital Universitario 12 de Octubre (Madrid), Hospital Miguel Servet (Saragossa), Hospital Materno Infantil Carlos Haya (Malaga), Hospital Universitario La Fe (Valencia), Hospital Universitario Virgen Macarena (Seville), Hospital del Mar (Barcelona), Hospital Infantil Universitario Niño Jesús (Madrid), Hospital Universitario Son Dureta (Palma de Mallorca), Hospital Severo Ochoa (Madrid), Hospital Universitario Nuestra Señora de Candelaria (Santa Cruz de Tenerife), Hospital Universitario de Canarias (La Laguna (Tenerife)), Hospital Basurto (Bilbao), Hospital Universitario Virgen de Las Nieves (Granada), HCU "Juan Canalejo" (Corunna), Complejo Hospitalario Universitario (Albacete), Hospital Gregorio Marañon (Madrid), Hospital Universitario Materno Infantil Vall d'Hebron (Barcelona), Hospital Donostia (San Sebastián); Slovakia: Comenuis University (Bratislava); Sweden: Bamkliniken (Karlskrana), Karolinska University Hospital-Huddinge (Stockholm), Sjukhuset (Västerviks), Queen Silvia Children's Hospital (Gothenburg), University Hospital (Lund), Lapplands Bamklinik (Gällivare), Barnallergimot NSK (Kungsbacha), Central Sjukhusset (Skovde), University Hospital (Orebro), Vrinnevi Hospital (Norrköping), Helsinborg Hospital (Helsinborg), Barukliniken (Soffetea), Central Sjukhusset (Kristanstad), University Hospital KEF (Linköping), Clinical Sciences (Malmö), Centrallasarettet (Västeras); Switzerland: University Children's Hospital (Berne), Hôpital régional (Sion), Hôpital du Chablais (Aigle), Ente Ospedaliero Cantonale (Ticino), Hôpital EHNV (Yverdon-Les-Bains), Hopital régional (Délémont), Dr. Ruettimann (Aarau), Kantonsspital (Chur), Centre Hospitalier Universitaire Vaudois (Lausanne), Hôpital régional (La-Chaux-De-Fonds), University Hospital (Geneva), University Children's Hospital (Zurich), Children's Hospital (Aarau), University Children's Hospital (Basel), Children's Hospital (St Gallen), Alpine Children's Hospital (Davos), Children's Hospital (Lucerne), Kantonsspital (Münsterlingen); Turkey: Marmara University Faculty of Medicine (Istanbul), Izzet Baysal University Hospital (Bolu), Dokuz Eylul University Hospital (Izmir), Cukurova University Faculty of Medicine (Adana), KTÜ Technical University Medical Faculty (Trabzon), Uludag University Medical Faculty (Bursa), Gaziantep University Faculty of Medicine (Gaziantep), Behcet Uz Training Hospital (Izmir), Dicle University Faculty of Medicine (Diyarbakir), Hacettepe University Faculty of Medicine (Ankara), Mersin University Faculty of Medicine (Mersin), Celal Bayar University Hospital (Manisa) Akdeniz University Hospital (Antalya), Gazi University Hospital (Ankara). 


\section{REFERENCES}

1 Bush A, Chodhari R, Collins N, et al. Primary ciliary dyskinesia: current state of the art. Arch Dis Child 2007; 92: 1136-1140.

2 Jain K, Padley SP, Goldstraw EJ, et al. Primary ciliary dyskinesia in the paediatric population: range and severity of radiological findings in a cohort of patients receiving tertiary care. Clin Radiol 2007; 62: 986-993.

3 Meeks M, Bush A. Primary ciliary dyskinesia (PCD). Pediatr Pulmonol 2000; 29: 307-316.

4 Noone PG, Leigh MW, Sannuti A, et al. Primary ciliary dyskinesia: diagnostic and phenotypic features. Am J Respir Crit Care Med 2004; 169: 459-467.

5 O'Callaghan C, Chilvers M, Hogg C, et al. Diagnosing primary ciliary dyskinesia. Thorax 2007; 62: 656-657.

6 Zariwala MA, Knowles MR, Omran H. Genetic defects in ciliary structure and function. Annu Rev Physiol 2006; 69: 423-450.

7 Stannard WA, Chilvers MA, Rutman AR, et al. Diagnostic testing of patients suspected of primary ciliary dyskinesia. Am J Respir Crit Care Med 2010; 181: 307-314.

8 Fliegauf M, Benzing T, Omran H. Cilia: hair-like oganelles with many links to disease. Nat Rev Mol Cell Bio 2007; 8: 880-893.

9 Coren ME, Meeks M, Morrison I, et al. Primary ciliary dyskinesia: age at diagnosis and symptom history. Acta Paediatr 2002; 91: 667-669.

10 Afzelius BA, Stenram U. Prevalence and genetics of immotile-cilia syndrome and left-handedness. Int J Dev Biol 2006; 50: 571-573.

11 Katsuhara K, Kawamoto S, Wakabayashi T, et al. Situs inversus totalis and Kartagener's syndrome in a Japanese population. Chest 1972; 61: 56-61.

12 Torgersen J. Transportation of viscera bronchiectasis and nasal polyps, genetical analysis and contribution to the problem of constitution. Acta Radiol 1947; 28: 17-24.

13 O'Callaghan C, Chetcuti P, Moya E. High prevalence of primary ciliary dyskinesia in a British Asian population. Arch Dis Child 2010; 95: 51-52.

14 Barbato A, Frischer T, Kuehni CE, et al. Primary ciliary dyskinesia: a consensus statement on diagnostic and treatment approaches in children. Eur Respir J 2009; 34: 1264-1276.

15 U.S. Census Bureau International Data Base (IDB). www.census. gov/ipc/www/idb/ Date last updated: December 12, 2008. Date last accessed: February 6, 2009.

16 United Nations, 2005. Definition of major areas and regions. http://esa.un.org/unpp/index.asp?panel=5 Date last updated: March 11, 2009. Date last accessed: February 6, 2009.
17 WHO. WHO Statistical Information System (WHOSIS). www. who.int/whosis/en/ Date last updated: February 6, 2009. Date last accessed: February 6, 2009.

18 Hornef $\mathrm{N}$, Olbrich $\mathrm{H}$, Horvath J, et al. DNAH5 mutations are a common cause of primary ciliary dyskinesia with outer dynein arm defects. Am J Respir Crit Care Med 2006; 174: 120-126.

19 Schwabe GC, Hoffmann K, Loges NT, et al. Primary ciliary dyskinesia associated with normal axoneme ultrastructure is caused by DNAH11 mutations. Hum Mutat 2008; 29: 289-298.

20 Chilvers MA, Rutman A, O'Callaghan C. Ciliary beat pattern is associated with specific ultrastructural defects in primary ciliary dyskinesia. J Allergy Clin Immunol 2003; 112: 518-524.

21 Kennedy MP, Omran H, Leigh MW, et al. Congenital heart disease and other heterotaxic defects in a large cohort of patients with primary ciliary dyskinesia. Circulation 2007; 115: 2814-2821.

22 Latzin P, Frey U, Roiha HL, et al. Prospectively assessed incidence, severity, and determinants of respiratory symptoms in the first year of life. Pediatr Pulmonol 2007; 42: 41-50.

23 Kühni CE, Sennhauser FH. The Yentl syndrome in childhood asthma: risk factors for undertreatment in Swiss children. Pediatr Pulmonol 1995; 19: 156-160.

24 Budny B, Chen W, Omran H, et al. A novel X-linked recessive mental retardation syndrome comprising macrocephaly and ciliary dysfunction is allelic to oral-facial-digital type I syndrome. Hum Genet 2006; 120: 171-178.

25 Moore A, Escudier E, Roger G, et al. RPGR is mutated in patients with a complex $\mathrm{X}$ linked phenotype combining primary ciliary dyskinesia and retinitis pigmentosa. J Med Genet 2006; 43: 326-333.

26 van Dorp DB, Wright AF, Carothers AD, et al. A family with RP3 type of X-linked retinitis pigmentosa: an association with ciliary abnormalities. Hum Genet 1992; 88: 331-334.

27 Ellerman A, Bisgaard H. Longitudinal study of lung function in a cohort of primary ciliary dyskinesia. Eur Respir J 1997; 10: 2376-2379.

28 Marthin JK, Petersen N, Skovgaard LT, et al. Lung function in patients with primary ciliary dyskinesia. A cross sectional and three-decade longitudinal study. Am J Respir Crit Care Med 2010; 181: 1262-1268.

29 Sims EJ, Mugford M, Clark A, et al. Economic implications of newborn screening for cystic fibrosis: a cost of illness retrospective cohort study. Lancet 2007; 369: 1187-1195. 